\title{
Anthracycline-based induction chemotherapy followed by concurrent cyclophosphamide, methotrexate and 5-fluorouracil and radiation therapy in surgically resected axillary node-positive breast cancer
}

\author{
FRANCESCO RECCHIA $^{1,2}$, GIAMPIERO CANDELORO ${ }^{1}$, ALISIA CESTA $^{1}$, MARIO DI STASO $^{3}$, \\ PIERLUIGI BONFILI ${ }^{3}$, GIOVANNI LUCA GRAVINA ${ }^{3}$, ERNESTO DI CESARE ${ }^{3}$, \\ STEFANO NECOZIONE ${ }^{4}$ and SILVIO REA ${ }^{5}$
${ }^{1}$ Department of Medical Oncology, Civilian Hospital, 67051 Avezzano, L'Aquila; ${ }^{2}$ Carlo Ferri Foundation, 00013 Monterotondo, Rome; ${ }^{3}$ Laboratory of Radiobiology and Division of Radiotherapy, Department of Applied Clinical and Biotechnological Sciences; Departments of ${ }^{4}$ Clinical Epidemiology and ${ }^{5}$ Surgical Oncology, University of L'Aquila, 67100 L'Aquila, L'Aquila, Italy

Received December 3, 2013; Accepted March 14, 2014

DOI: $10.3892 / \mathrm{mco} .2014 .269$

\begin{abstract}
The present study aimed to determine the toxicity and efficacy of 4 courses of anthracyclines-taxane (AT) chemotherapy followed by radiation therapy (XRT) concurrent with cyclophosphamide, methotrexate and 5-fluorouracil (CMF) in surgically resected axillary node-positive $(\mathrm{N}+)$ breast cancer. A total of 200 women with $\mathrm{N}+$ breast cancer were treated with adriamycin and docetaxel followed by XRT concurrent with six courses of CMF. Two courses of dose-dense chemotherapy with ifosfamide, carboplatin and etoposide, supported by pegfilgrastim, were administered to patients with $>5$ histologically confirmed axillary lymph node metastases and patients with triple-negative disease. Additional treatments included 1 year of trastuzumab in human epidermal growth factor receptor 2-positive patients, 5 years of a luteinizing hormone-releasing hormone analogue in premenopausal women and 5 years of an aromatase inhibitor (AI) in estrogen receptor-positive (ER+) patients. The mean number of positive axillary lymph nodes was 4.4 (range, 2-37), $52 \%$ of the patients were premenopausal, $74 \%$ were ER+ and $26 \%$ had triple-negative disease. After a median follow-up of 73 months, grade 2 and 3 hematological toxicity was observed in $20 \%$ of the patients. The 10 -year disease-free survival (DFS) and overall survival (OS) rates were 73 and 77\%, respectively. There was no significant difference in DFS between ER+ and
\end{abstract}

Correspondence to: Dr Francesco Recchia, Department of Medical Oncology, Civilian Hospital, 36 Via G. Di Vittorio, 67051 Avezzano, L'Aquila, Italy

E-mail: frecchia1946@libero.it

Key words: node-positive breast cancer, surgery, chemotherapy, radiation therapy estrogen receptor-negative (ER-) patients $(\mathrm{P}>0.05)$, whereas the OS was better in ER+ vs. ER-patients $(\mathrm{P}<0.05)$ and in premenopausal vs. postmenopausal patients $(\mathrm{P}<0.005)$. In conclusion, induction AT concurrent CMF and XRT and dose-dense chemotherapy followed by AI in N+ high-risk breast cancer was associated with a low level of systemic and late cardiac toxicity and excellent local control, DFS and OS.

\section{Introduction}

A number of randomized trials with a prolonged follow-up reported that breast-conserving surgery (BCS) and modified radical mastectomy (MRM) have comparable overall survival (OS) rates $(1,2)$. The standard treatment for operable breast cancer is currently BCS followed by postoperative radiation therapy (XRT) (1). Several previous randomized trials demonstrated that adjuvant chemotherapy improves disease-free survival (DFS) and OS in axillary node-positive $(\mathrm{N}+)$ high-risk breast cancer patients (3). In the adjuvant setting, it has been observed an advantage of anthracycline-based over non-anthracycline-based chemotherapeutic regimens for $\mathrm{N}+$ high-risk breast cancer (4). However, XRT administered concomitantly with anthracycline-based chemotherapy may be associated with excessive cardiac toxicity $(1,5)$. It was previously suggested that the local recurrence rate may be higher when the initiation of XRT is delayed (6). Although the administration of adjuvant chemotherapy prior to XRT has become common practice for patients with early-stage breast cancer who undergo conservative surgery, the optimal integration of chemotherapy and XRT remains controversial. To avoid delaying the administration of XRT following administration of adriamycin and docetaxel, we sought to deliver cyclophosphamide, methotrexate and 5-fluorouracil (CMF) chemotherapy concomitantly with XRT. In high-risk breast cancer, the concurrent administration of both treatments may be feasible by selectively using drugs that do not have 
cumulative toxic effects with XRT. Such a scheme may have the advantage of exerting synergistic effects on tumor response and shortening the delay in initiating XRT, with obvious survival benefits. A randomized phase III trial of patients with $\mathrm{N}+$ breast cancer demonstrated that the 5-year locoregional relapse-free survival decreased by $39 \%$ in the concurrent chemotherapy-XRT arm compared to the sequential arm (7). In addition, the mortality risk associated with XRT is minor compared to its survival benefit. In the latest Oxford Overview, XRT following mastectomy and axillary node dissection provided an $11.4 \%$ absolute gain in the 10 -year recurrence-free survival and a $9.4 \%$ gain in the 15 -year breast cancer mortality in patients with 1-3 positive nodes (8). Based on those findings, a phase II trial was designed in order to investigate sequential adriamycin, docetaxel and CMF concurrent with XRT in patients who undergo surgical resection. The schedule was personalized for patients with the highest risk of relapse, such as women with $>5$ positive axillary nodes and women with triple-negative disease (9). Those patients received a dose-dense chemotherapeutic regimen including carboplatin, ifosfamide and etoposide, which was previously shown to be efficient at both the standard (10) and high doses (11) in breast cancer patients previously treated with anthracyclines.

\section{Patients and methods}

Eligibility. This multicenter, phase II, single-arm study included premenopausal and postmenopausal breast cancer patients, aged 24-70 years, who were treated with MRM or BCS and axillary node dissection. All the subjects had high-risk, invasive pT2-pT3a breast cancer with $>1$ positive axillary lymph nodes and no distant metastasis. Continuing ovarian function was biochemically confirmed by the following laboratory data: follicle-stimulating hormone $<10 \mathrm{mU} / \mathrm{ml}$; luteinizing hormone (LH) $<0.8 \mathrm{mU} / \mathrm{ml}$; $17 \beta$-estradiol (E2), 20-693 pg/ml; and progesterone, $0.15-28 \mathrm{ng} / \mathrm{ml}$. Other eligibility criteria included an Eastern Cooperative Oncology Group performance status of $0-1$ and adequate baseline bone marrow function (absolute neutrophil count $>1,500 / \mathrm{ml}$, platelet count $>100,000$ cells $/ \mathrm{ml}$ ), hepatic function [serum bilirubin $<2.0 \mathrm{mg} / \mathrm{dl}$, transaminase (aspartate aminotransferase, alanine aminotransferase) levels $<5 \mathrm{x}$ the upper limit of institutional norm] and renal function (creatinine $<1.4 \mathrm{mg} / \mathrm{dl}$ ). Patients with histotypes characterized by a more indolent behavior (papillary, medullary or mucinous), metastases, or malignancies other than curatively treated skin and cervical cancer were excluded. This phase II study was performed in accordance with the Declaration of Helsinki and the European Union Guidelines on Good Clinical Practice and was approved by the Ethics Committees of the participating institutions. Written informed consent was obtained from each patient. Immediately after surgery and throughout the 5 years covered by the study, the patients received psychological support to improve treatment compliance.

Surgical and medical treatment. The patients underwent a surgical procedure consisting of either MRM or BCS. Patients with $\mathrm{N}+$ disease were treated as follows: starting 2 weeks after surgery, premenopausal patients received an LH-releasing hormone (LH-RH) analogue $(11.25 \mathrm{mg})$ by deep intramuscular injection every 12 weeks for 5 years (12) and chemotherapy was initiated 2 weeks after the LH-RH analogue. The initiation of cytotoxic therapy was delayed for 3 weeks after surgery in postmenopausal patients and consisted of 4 courses of adriamycin $\left(50 \mathrm{mg} / \mathrm{m}^{2}\right)$ and docetaxel $\left(75 \mathrm{mg} / \mathrm{m}^{2}\right)$ every 3 weeks. Concurrently with XRT, 6 courses of CMF $\left(600 \mathrm{mg} / \mathrm{m}^{2}\right.$ cyclophosphamide, $600 \mathrm{mg} / \mathrm{m}^{2}$ 5-fluorouracil and $60 \mathrm{mg} / \mathrm{m}^{2}$ methotrexate) were administered every 3 weeks. XRT was administered to all the patients at a total dose of 5,000 cGy (200 cGy/fraction, 5 fractions/week) to the chest wall following mastectomy or to the residual breast tissue following BCS. Irradiation (5,000 cGy in $200 \mathrm{cGy} / \mathrm{frac}-$ tion, 5 fractions/week) of the axillary (II and III levels) and supraclavicular lymph nodes was performed in patients with $>4$ histologically confirmed axillary lymph node metastases. A boost of 1,000 cGy was delivered to the tumor bed. One month after completion of the chemoradiation therapy, patients with $>5$ histologically confirmed axillary lymph node metastases $(n=30)$ and patients with triple-negative disease $(n=38)$ received 2 courses of dose-dense chemotherapy with ifosfamide $\left(5 \mathrm{~g} / \mathrm{m}^{2}\right)$, carboplatin (area under the concentration-time curve $=7)$ and etoposide $\left(300 \mathrm{mg} / \mathrm{m}^{2}\right)$, supported by $300 \mu \mathrm{g} /$ day of glycosylated recombinant granulocyte colony-stimulating factor, without peripheral blood progenitor cell support $(11,13)$. Estrogen receptor-positive (ER+) patients received an aromatase inhibitor for 5 years.

Statistical analysis. The number of patients required for the study was calculated according to Simon's two-stage design (14). The first stage required that $\geq 80$ of 128 patients exhibited an improvement from $60 \%$ (P0) to $70 \%$ (P1) in the expected 5-year DFS of $\mathrm{N}+$ breast cancer (P1), with a $5 \%$ one-sided type I error $(\alpha)$ and with a $90 \%$ statistical power (1- $\beta$ ). In the second stage, a total of 200 assessable patients could be added, if $\geq 130$ patients exhibited an improvement in DFS. All the analyses were performed on an intent-to-treat basis. DFS was defined as the time from the initiation of adjuvant chemotherapy until objective disease progression or death. The OS was calculated from the initiation of adjuvant chemotherapy until death from any cause. The DFS and OS were calculated using the Kaplan-Meier life table method (15). The survival curves for patient subgroups were compared using the log-rank test (16). Data analyses were performed on May 31, 2013. An adjusted $\mathrm{P}<0.05$ was considered to indicate a statistically significant difference. All the tests were two-sided unless otherwise specified. All the statistical analyses were performed using the SPSS $^{\circledR}$ statistical analysis software, version 10.0 (SPSS, Inc., Chicago, IL, USA).

\section{Results}

Patient characteristics. A total of 200 women were recruited between March, 1998 and August, 2010. The median age was 55 years (range, $24-70$ years) and $52 \%(n=103)$ of the patients were premenopausal. Stage II and III breast cancer was diagnosed in 63 and $37 \%$ of patients, respectively. In total, $76 \%$ of patients were treated with BCS, whereas $24 \%$ underwent MRM. The median number of recovered positive axillary lymph nodes was 4.4 (range, 2-37). The majority (74\%) of the patients were $\mathrm{ER}+$ and $26 \%$ were estrogen receptor-negative (ER-). The median Ki-67 index was 30\% (range, 10-100\%). Of 
Table I. Patient characteristics.

\begin{tabular}{|c|c|c|}
\hline Characteristics & No. & Percentage \\
\hline No. of patients & 200 & 100.0 \\
\hline \multicolumn{3}{|l|}{ Age, years } \\
\hline Median & 55 & \\
\hline Range & $24-70$ & \\
\hline \multicolumn{3}{|c|}{ ECOG performance status } \\
\hline 0 & 180 & 90.0 \\
\hline 1 & 20 & 10.0 \\
\hline \multicolumn{3}{|l|}{ Grading } \\
\hline G1 and mucinous & 16 & 8.0 \\
\hline $\mathrm{G} 2$ & 106 & 53.0 \\
\hline G3 & 78 & 39.0 \\
\hline \multicolumn{3}{|c|}{ Hormone receptor status } \\
\hline $\mathrm{ER}+$ & 148 & 74.0 \\
\hline ER- & 52 & 26.0 \\
\hline \multicolumn{3}{|l|}{ HER status (FISH) } \\
\hline Positive & 41 & 20.5 \\
\hline Negative & 159 & 79.5 \\
\hline \multicolumn{3}{|l|}{$\mathrm{Ki}-67$ index, $\%$} \\
\hline Median & 30 & \\
\hline Range & $10-100$ & \\
\hline \multicolumn{3}{|l|}{ Clinical stage } \\
\hline IIA & 94 & 47.0 \\
\hline IIB & 32 & 16.0 \\
\hline IIIA & 30 & 15.0 \\
\hline IIIB & 14 & 7.0 \\
\hline IIIC & 30 & 15.0 \\
\hline \multicolumn{3}{|c|}{ Type of primary surgery } \\
\hline Mastectomy & 47 & 23.5 \\
\hline Quadrantectomy & 153 & 76.5 \\
\hline \multicolumn{3}{|l|}{ Menstrual status } \\
\hline Premenopausal & 103 & 51.5 \\
\hline Postmenopausal & 97 & 48.5 \\
\hline
\end{tabular}

ECOG, Eastern Cooperative Oncology Group; ER, estrogen receptor; HER2, human epidermal growth factor receptor 2; FISH, fluorescence in situ hybridization.

the 41 patients with human epidermal growth factor receptor 2 (HER2)-positive tumors, 28 were treated with trastuzumab after 2006; the remaining 13 patients did not receive trastuzumab, as their treatment occurred prior to its approval as adjuvant therapy. The mean baseline characteristics of the patients are summarized in Table I. All the patients were included in the study according to the intent-to-treat principle.

Treatment efficacy. After a median follow-up of 73 months (range, 38-180 months), all the patients were evaluable for toxicity and efficacy. The median DFS and OS had not yet been reached. In total, $42(21 \%)$ subjects experienced disease progression, corresponding to a 10 -year DFS rate of $73.8 \%$

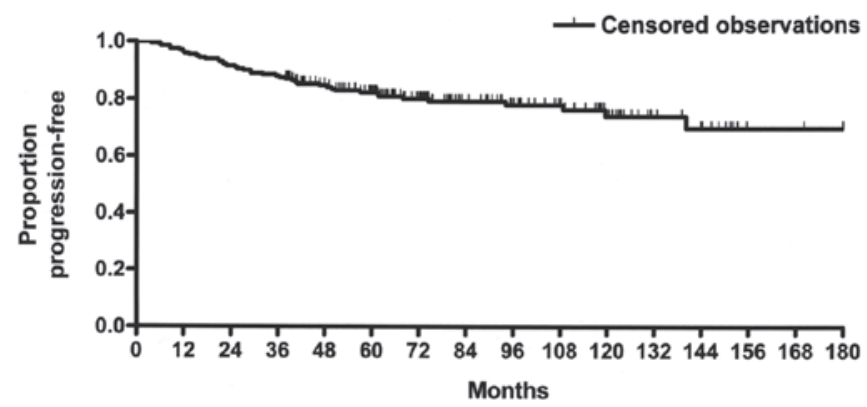

Figure 1. Overall disease-free survival (DFS). Median follow-up, 73 months (range, 38-180 months). The figure presents 42 events (21\%), 158 censored observations (79\%) and a 10-year PFS rate of $73.8 \%$.

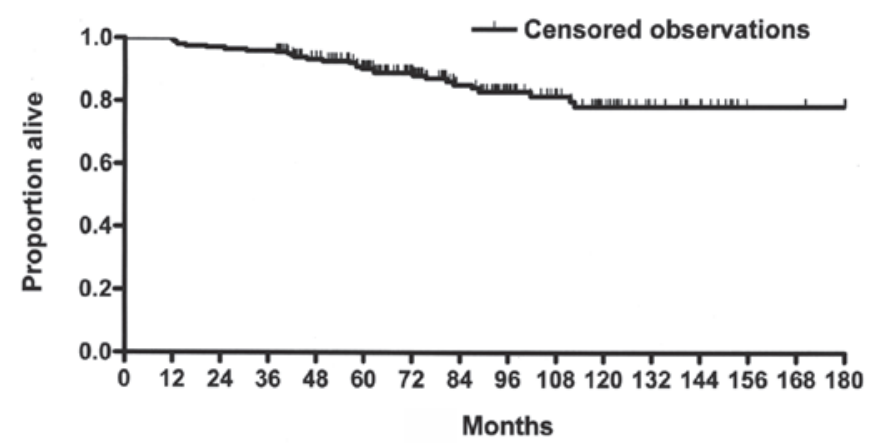

Figure 2. Overall survival (OS). The median follow-up was 73 months (range, 38-180 months). The figure presents 29 events (14.5\%), 171 censored observations $(85.5 \%)$ and a 10 -year OS rate of $77.3 \%$.

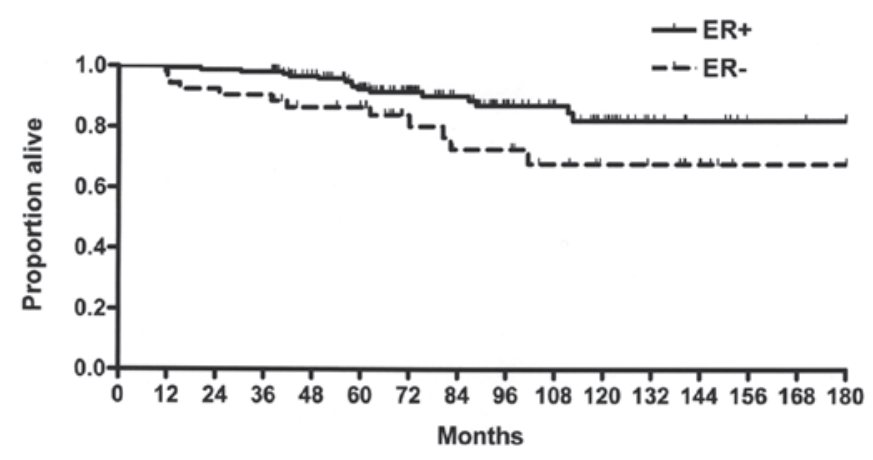

Figure 3. Overall survival of estrogen receptor-positive (ER+) vs. estrogen receptor-negative (ER-) patients. $\mathrm{P}<0.005$.

(Fig. 1). The corresponding 5- and 15-year DFS rates were 82.3 and $69.5 \%$, respectively. There were a total of 29 deaths (14.5\%), corresponding to a 10 -year OS rate of $77.3 \%$ (Fig. 2). The parallel 5- and 15-year OS rates were 92.2 and $77.3 \%$, respectively. There were no significant differences between the DFS of ER+ (80.7) and ER- (62.8\%) patients $(\mathrm{P}=0.088)$; however, the difference in OS between ER+ (80.7) and ER$(67.6 \%)$ patients was significant $(\mathrm{P}<0.005$; Fig. 3$)$. The 5-year DFS rate was $88.3 \%$ in premenopausal and $75 \%$ in postmenopausal patients and the corresponding 15-year DFS rate was $80.8 \%$ in premenopausal and $54.5 \%$ in postmenopausal patients $(\mathrm{P}<0.05)$. The 15-year OS rate was also improved in premenopausal (86.7) compared to that in postmenopausal patients (70.8\%, $\mathrm{P}<0.05$; Fig. 4). There were significant differences in 
Table II. Treatment toxicities.

Type of treatment

\begin{tabular}{|c|c|c|c|c|}
\hline \multirow[b]{2}{*}{ Adverse events } & \\
\hline & $\begin{array}{l}\text { LH-RH analogue } \\
\qquad(\mathrm{n}=96) \\
\mathrm{n}(\%)\end{array}$ & $\begin{array}{l}\text { Anthracycline-taxanes } \\
\qquad(\mathrm{n}=200) \\
\mathrm{n}(\%)\end{array}$ & $\begin{array}{c}\text { CMF+XRT } \\
(\mathrm{n}=200) \\
\mathrm{n}(\%)\end{array}$ & $\begin{array}{l}\text { DD-CT } \\
(\mathrm{n}=68) \\
\mathrm{n}(\%)\end{array}$ \\
\hline \multicolumn{5}{|l|}{ Hematological } \\
\hline Leukopenia & $0(0)$ & $64(32)$ & $6(3)$ & $68(100)$ \\
\hline Thrombocytopenia & $0(0)$ & $18(9)$ & $0(0)$ & $68(100)$ \\
\hline Anemia & $0(0)$ & $18(9)$ & $0(0)$ & $12(18)$ \\
\hline \multicolumn{5}{|l|}{ Gastrointestinal } \\
\hline Nausea-vomiting & $0(0)$ & $38(19)$ & $26(13)$ & $18(27)$ \\
\hline Diarrhea & $0(0)$ & $22(11)$ & $6(3)$ & $9(13)$ \\
\hline Mucositis & $0(0)$ & $22(11)$ & $16(8)$ & $0(0)$ \\
\hline Infection & $0(0)$ & $4(2)$ & $0(0)$ & $9(13)$ \\
\hline Neurotoxicity (grade 2) & $0(0)$ & $30(15)$ & $0(0)$ & $0(0)$ \\
\hline Alopecia & $0(0)$ & $200(100)$ & $0(0)$ & $68(100)$ \\
\hline Hot flashes & $86(90)$ & $0(0)$ & $0(0)$ & $0(0)$ \\
\hline
\end{tabular}

LH-RH, luteinizing hormone-releasing hormone; CMF, cyclophosphamide, methotrexate and 5-fluorouracil; XRT, radiation therapy; DD-CT, dose-dense chemotherapy.

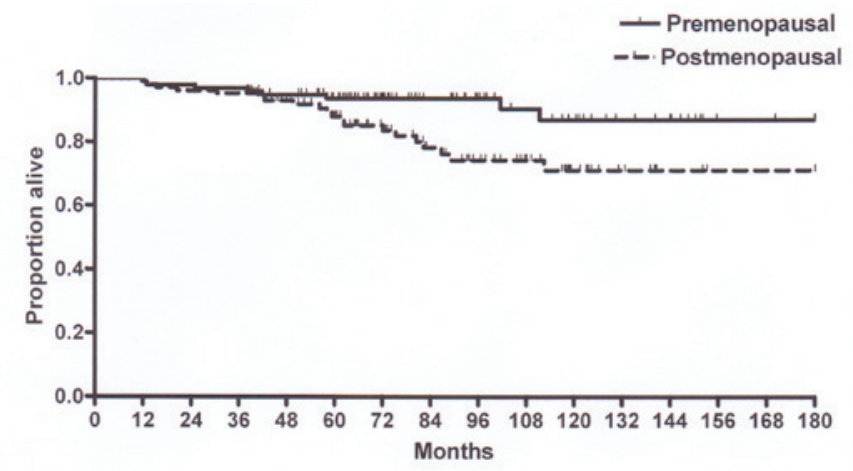

Figure 4. Overall survival of premenopausal vs. postmenopausal patients. $\mathrm{P}<0.05$.

the DFS $(\mathrm{P}<0.0001)$ and the OS $(\mathrm{P}<0.0001)$ (Fig. 5) between patients with $>5$ and those with $<5$ histologically-confirmed axillary lymph node metastases. A total of 6 patients suffered from recurrence (3 ER+ and $3 \mathrm{ER}$ - patients) after a median time of 31.3 months. Tumor recurrence occurred locoregionally in 3 cases, in the brain and lung in 2 cases and in osseous tissue in 1 case. A total of 3 patients with recurrence had $>10$ positive axillary nodes and the remaining 3 were HER2-positive and were not treated with trastuzumab.

Toxicity. The adverse events are summarized in Table II. Toxicity grading was performed according to the National Cancer Institute-Common Terminology Criteria for Adverse Events, version 3.0. The delivered dose intensities were as follows: 95\% for docetaxel and adriamycin, $98 \%$ for $\mathrm{CMF}$ and $98 \%$ for dose-dense chemotherapy. In total, $90 \%$ of the patients treated with LH-RH analogues experienced hot

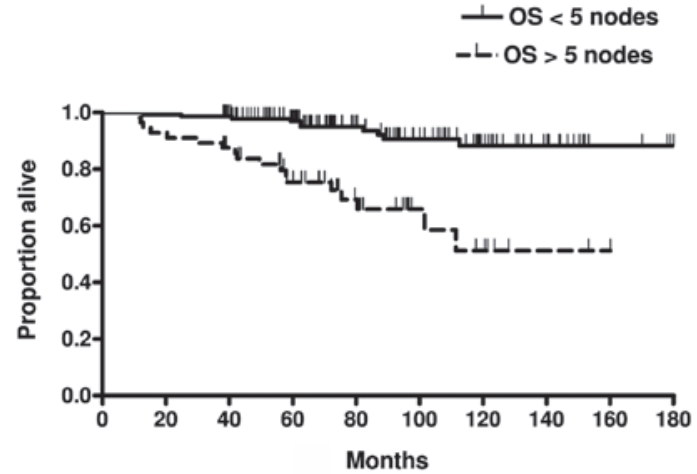

Figure 5. Overall survival (OS) of patients with more or less than five histologically confirmed axillary lymph node metastases. $\mathrm{P}<0.0001$.

flashes, mood modification and vaginal dryness. The bone mineral density was assessed at baseline and annually thereafter. The median T-score was -1.3 (range, -2 to 1.5 ) at baseline and -2.0 (range, -4 to -1.2) in the fifth year of LH-RH analogue treatment. Arthralgias and muscle weakness were common but did not interfere with daily activities. Upon anthracycline chemotherapy, grade 3-4 hematological toxicity was observed in 64 patients $(32 \%)$, whereas thrombocytopenia and anemia were each observed in $18 \%$ of the patients. Alopecia was universal. Only 6 patients $(3 \%)$ required discontinuation of concomitant XRT and CMF for 1 week due to leukopenia, whereas gastrointestinal toxicity and mucositis were observed in 13 and $8 \%$ of the patients, respectively. In dose-dense chemotherapy, nausea and vomiting were observed in 6 cases; however, they were mild and manageable with ondansetron and dexamethasone. Grade 4 leukopenia and thrombocytopenia were observed in all 68 patients undergoing dose-dense 
chemotherapy. The absolute neutrophil count was $<5 \times 10^{3} / \mathrm{ml}$ for a median of 4.5 days (range, 3-5 days) and the platelet count was $<50 \times 10^{3} / \mathrm{ml}$ for a median of 1 day (range, 0-3 days). No patients required platelet transfusion. There was no reported cardiac toxicity or significant reduction of the left ventricular ejection fraction. Anemia was infrequent due to the use of erythropoietin and occurred in only 4 patients (18\%). A total of 3 patients developed a fever $>38^{\circ} \mathrm{C}$ for a median duration of 3 days (range, 0-6 days). Grade 2 mucositis and grade 3 diarrhea occurred in 4 and 3 patients, respectively. One patient had a documented infection, with a positive blood culture for Staphylococcus epidermidis. A total of 2 patients suffered from bone pain, with a median duration of 2 days. There were no reported treatment-related deaths.

\section{Discussion}

Advances in medical oncology, including several approaches to adjuvant treatment, have improved the prognosis of breast cancer patients. In particular, the integration of surgery with different treatments, such as chemotherapy and XRT, has decreased local and systemic recurrence.

The role of concurrent chemotherapy and XRT has been well established in the treatment of several types of tumors, including cancer of the esophagus, stomach, pancreas, head and neck and lungs; however, its role in the treatment of breast cancer remains unclear and the optimal sequence of chemotherapy and XRT has not yet been determined. Toledano et al (7) reported a significant reduction of $39 \%$ in the risk of locoregional recurrence in $\mathrm{N}+$ breast cancer with the administration of concurrent XRT and chemotherapy, with respect to their sequential administration. Another important issue is the delay in initiating XRT following chemotherapy. It was reported that delaying the initiation of intact breast irradiation for patients with $\mathrm{N}+$ breast cancer increases the risk of local recurrence $(17,18)$.

A recently published Cochrane Database Review indicated that different methods of sequencing chemotherapy and XRT do not appear to exert a major effect on recurrence or survival in women with breast cancer, provided that XRT is initiated within 7 months of surgery (19). However, 10 months are likely to elapse between surgery and XRT if anthracycline-taxane-based therapy followed by 6 courses of CMF is administered.

In high-risk breast cancer with the involvement of $\geq 4$ axillary nodes, intense dose-dense chemotherapy may be superior to conventional chemotherapy (20). A previous study reported that, after a median follow-up of 62 months, the 5-year event-free survival rates were $62 \%$ in the conventional and $70 \%$ in the dose-dense chemotherapy arms, representing a $28 \%$ reduction in the relative risk of relapse $(\mathrm{P}<0.001)(20)$. This benefit was independent of the menopausal, hormone receptor or HER2 status. In addition, the 5-year OS rates were 77 vs. $82 \%$, representing a $24 \%$ reduction in the relative mortality risk $(\mathrm{P}=0.0285)$.

In the present study, the adjuvant therapy was very successful in patients with 1-5 positive axillary lymph nodes. As regards high-risk patients with $>5$ positive axillary nodes who were treated with two platinum-based dose-dense regimens, a significant difference was observed in the DFS and OS between patients with $>5$ and those with $<5$ positive axillary nodes. These results indicate that researchers should seek new methods of improving the results of adjuvant therapy in this group of patients with high-risk breast cancer.

In our non-randomized multicenter phase II study, the patients were accrued consecutively for 12 years, with no selection bias. Only $\mathrm{N}+$ patients were accrued. In contrast to other studies, our protocol planned the administration of LH-RH analogues concurrently with chemotherapy and XRT in premenopausal patients (12). Particularly good results were obtained in the 103 premenopausal patients. Prior to chemotherapy initiation, these patients were treated with an LH-RH analogue, which was continued for 5 years (12). With this approach, we used the two most significant modalities in the treatment of premenopausal patients with breast cancer, total estrogen blockade and chemotherapy (21). High blood estrogen levels are a relevant risk factor for the development of breast cancer. The Nurses' Health Study II demonstrated that the highest follicular total and free E2 levels are associated with a significantly increased risk of breast cancer (22).

In conclusion, we demonstrated that XRT administered concomitantly with CMF chemotherapy is a feasible therapeutic option, is not associated with excessive toxicity and allows XRT to be initiated within 7 months of surgery (17).

\section{References}

1. Veronesi U, Cascinelli N, Mariani L, Greco M, Saccozzi R, Luini A, Aguilar M and Marubini E: Twenty-year follow-up of a randomized study comparing breast-conserving surgery with radical mastectomy for early breast cancer. N Engl J Med 347: 1227-1232, 2002.

2. Fisher B, Anderson S, Bryant J, Margolese RG, Deutsch M, Fisher ER, Jeong JH and Wolmark N: Twenty year follow-up of a randomized trial comparing total mastectomy, lumpectomy, and lumpectomy plus irradiation for the treatment of invasive breast cancer. N Engl J Med 347: 1233-1241, 2002.

3. Early Breast Cancer Trialists' Collaborative Group (EBCTCG): Effects of chemotherapy and hormonal therapy for early breast cancer on recurrence and 15-year survival: an overview of the randomised trials. Lancet 365: 1687-1717, 2005.

4. Early Breast Cancer Trialists' Collaborative Group (EBCTCG), Peto R, Davies C, Godwin J, et al: Comparisons between different polychemotherapy regimens for early breast cancer: meta-analyses of long-term outcome among 100,000 women in 123 randomised trials. Lancet 379: 432-444, 2012.

5. Darby SC, Ewertz M, McGale P, et al: Risk of ischemic heart disease in women after radiotherapy for breast cancer. N Engl J Med 368: 987-998, 2013.

6. Recht A, Come SE, Gelman RS, et al: Integration of conservative surgery, radiotherapy, and chemotherapy for the treatment of early-stage, node-positive breast cancer: sequencing, timing, and outcome. J Clin Oncol 9: 1662-1667, 1991.

7. Toledano A, Azria D, Garaud P, Fourquet A, Serin D, Bosset JF, Miny-Buffet J, Favre A, Le Floch O and Calais G: Phase III trial of concurrent or sequential adjuvant chemoradiotherapy after conservative surgery for early-stage breast cancer: final results of the ARCOSEIN trial. J Clin Oncol 25: 405-410, 2007.

8. Early Breast Cancer Trialists' Collaborative Group (EBCTCG), Darby S, McGale P, Correa C, et al: Effect of radiotherapy after breast-conserving surgery on 10 -year recurrence and 15 -year breast cancer death: meta-analysis of individual patient data for 10,801 women in 17 randomised trials. Lancet 378: 1707-1716, 2011.

9. Rodenhuis S, Bontenbal M, Beex LV, et al: High-dose chemotherapy with hematopoietic stem-cell rescue for high-risk breast cancer. N Engl J Med 349: 7-16, 2003.

10. Recchia F, Nuzzo A, Lalli A, De Filippis S and Torchio P: Activity of standard-dose carboplatin, cyclophosphamide, and etoposide in patients with metastatic breast cancer with previous exposure to anthracyclines. Am J Clin Oncol 20: 166-168, 1997.

11. Recchia F, De Fillipis S, Piccinini M and Rea S: High-dose carboplatin, cyclophosphamide, etoposide with hematological growth factors, without stem cell support in patients with advanced cancer. Anticancer Res 23: 4141-4147, 2003. 
12. Recchia F, Saggio G, Amiconi G, Di Blasio A, Cesta A, Candeloro $\mathrm{G}$ and Rea S: Gonadotropin-releasing hormone analogues added to adjuvant chemotherapy protect ovarian function and improve clinical outcomes in young women with early breast carcinoma. Cancer 106: 514-523, 2006.

13. Recchia F, Candeloro G, Desideri G, Necozione S, Recchia CO, Cirulli V and Rea S: Triple-negative breast cancer: multipronged approach, single-arm pilot phase II study. Cancer Med 1: 89-95, 2012.

14. Simon R: Confidence intervals for reporting results of clinical trials. Ann Intern Med 105: 429-435, 1986.

15. Kaplan EL and Meyer P: Nonparametric estimation from incomplete observation. J Am Stat Assoc 53: 457-481, 1958.

16. Cox DR: Regression models and Life-Tables. J R Stat Soc 34: 187-220, 1972

17. Hartsell WF, Recine DC, Griem KL and Murthy AK: Delaying the initiation of intact breast irradiation for patients with lymph node positive breast cancer increases the risk of local recurrence. Cancer 76: 2497-2503, 1995.

18. Buchholz TA, Austin-Seymour MM, Moe RE, Ellis GK, Livingston RB, Pelton JG and Griffin TW: Effect of delay in radiation in the combined modality treatment of breast cancer. Int J Radiat Oncol Biol Phys 26: 23-35, 1993.
19. Hickey BE, Francis DP and Lehman M: Sequencing of chemotherapy and radiotherapy for early breast cancer. Cochrane Database Syst Rev 4: doi: 10.1002/14651858.CD005212.pub3.

20. Moebus V, Jackisch C, Lueck HJ, et al: Intense dose-dense sequential chemotherapy with epirubicin, paclitaxel, and cyclophosphamide compared with conventionally scheduled chemotherapy in high-risk primary breast cancer: mature results of an AGO phase III study. J Clin Oncol 28: 2874-2880, 2010.

21. Recchia F, Candeloro G, Necozione S, Desideri G, Cesta A, Recchia L and Rea S: Vascular endothelial growth factor expression and T-regulatory cells in premenopausal breast cancer. Oncol Lett 5: 1117-1122, 2013.

22. Eliassen AH, Missmer SA, Tworoger SS, Spiegelman D, Barbieri RL, Dowsett $M$ and Hankinson SE: Endogenous steroid hormone concentrations and risk of breast cancer among premenopausal women. J Natl Cancer Inst 98: 1406-1415, 2006. 